\title{
Simulation and analysis of the possibilities of traction electric motor
}

\author{
Ayman Y. Al-Rawashdeh \\ Department of Electrical Engineering, Faculty of Engineering Technology, Al-Balqa Applied University, Amman, Jordan
}

\begin{tabular}{|c|c|}
\hline Article Info & ABSTRACT \\
\hline Article history: & \multirow{11}{*}{$\begin{array}{l}\text { Great efforts are directed towards the use of electrical vehicles in } \\
\text { transportation. Mathematical modeling tools can provide a powerful } \\
\text { approach for investigating electrical vehciles and are successfully } \\
\text { implemented by applying Matlab/Simulink. In this paper, the mathematical } \\
\text { simulation model of Series Excited DC motor (tractive motor) on } \\
\text { Matlab/Simulink was implemented and investigated. The main objective of } \\
\text { this study is to assess the use of Series Excited DC motor (tractive motor) for } \\
\text { the new Amman city express bus project and evaluation of its performance } \\
\text { characteristics in different running and loading cases. All simulation results } \\
\text { are plotted and discussed. Simulation results showed that Series tractive DC } \\
\text { Motor is very suitable in electric (Buses) transport devices. The starting } \\
\text { current was about } 460 \text { A, ( } 8 \text { times more than the rated motor current) and } 357 \\
\text { A in steady state condition with different loads (passengers). This study } \\
\text { confirms the feasibility for the use of the series excited DC motor (tractive } \\
\text { motor) in electric buses as alternatives for sustaibale and environmentally } \\
\text { friendly transportation system. }\end{array}$} \\
\hline Received Jun 17, 2018 & \\
\hline Revised Aug 21, 2018 & \\
\hline Accepted Nov 18, 2018 & \\
\hline & \\
\hline Keywords: & \\
\hline Electric transportation & \\
\hline Matlab/simulink modeling & \\
\hline Modeling & \\
\hline Series excited DC motor & \\
\hline Tractive motor & \\
\hline
\end{tabular}

Copyright $\odot 2019$ Institute of Advanced Engineering and Science.

\section{All rights reserved.}

\section{Corresponding Author:}

Ayman Y. Al-Rawashdeh,

Department of Electrical Engineering, Faculty of Engineering Technology,

Al-Balqa Applied University, Amman, Jordan.

Email: dr.ayman.rawashdeh@bau.edu.jo,

\section{INTRODUCTION}

Public transportation nowadays is one of the most encountered daily problems in most cities of the world. Due to many factors including world fuel crises, environmental concerns, there was a demand for fuel economy and environment friendly transportation vehicles [1]. Electric Vehicles (EV) and Electric Transport Systems (ETS) had acquired great attention and are predicted to be the most used mode of transportation in the near future, due to their advantages as compared to ordinary transportation vehicles [2]. These vehicles are economic with low running coasts and maintenance, have better performance capabilities as compared to conventional internal combustion engine vehicles. Since these vehicles use no fuel, they are predicted to reduce harmful carbon emissions by $25-60 \%$ and thus reducing pollution and greenhouse gases. Moreover, the use of renewable energy for charging is an important option that helps in reducing fuel problems. In comparison with an internal combustion engine, electric motor has high efficiency and lower energy losses. The efficiency of the electric motor is about $90 \%$ against $25 \%$ of an internal combustion engine. Researchers are continuously working on ETS and EV to improve their range, performance and reliability [3]. In this field, the ongoing research efforts are focused on increasing the life time of the battery bank [4] that provides the advantages of low power rated converter and better load profile for the battery bank. Clegg (1996) [5] indicated that the energy efficiency can be amplified by using regenerative braking of motors (tractive motor) [6]. His results indicated a good dynamic performance and robust stability with more recovered energy. Accordingly, regenerative braking appears to be suitable for hybrid electric vehicles and for fuel cell electric vehicles as well [7]. 
Recently, in the Capital city of Jordan, Amman, a two lane Express Bus Project of $25 \mathrm{~km}$ long has been lunched [8]. The express bus project, in its current form Figure 1 employs the use of fossil energy sources (Diesel).

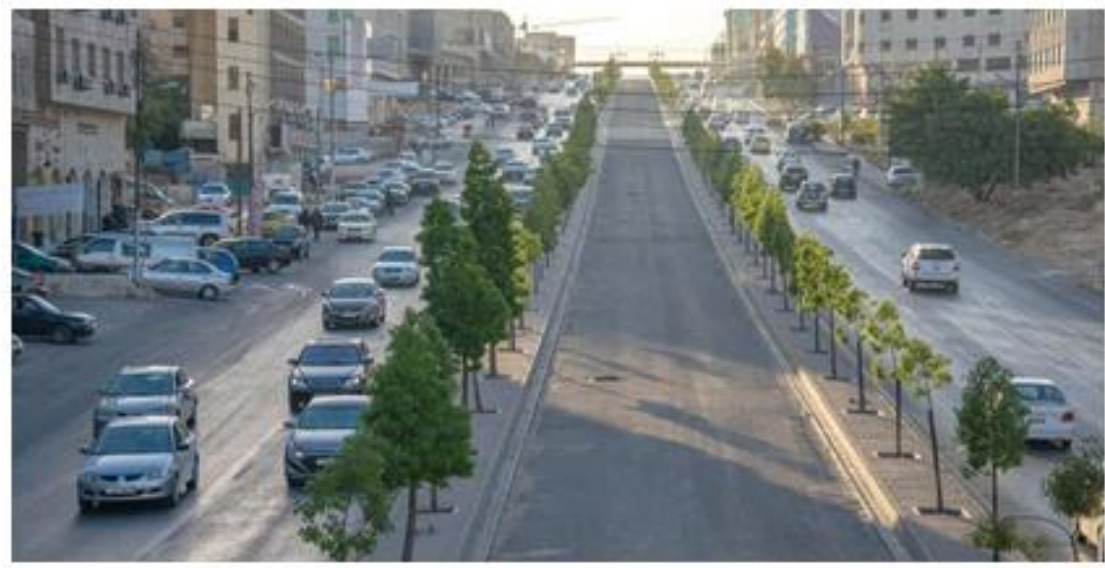

Figure 1. A view of Amman Express Bus Project

However, the current investigation suggests the use of electric buses and the better investment of the French funding [9] in establishing the electrical network required for this project. Moreover, the study also suggests the use of traction electric motors instead of internal combustion engine motors that requirs fossile fuel (diesel), taking into consideration the geographical nature of Amman and the possibility of employing solar energy to generate the electricity required for running these electric buses.

The main requirements of a traction electric motor are:

a) The ability to realize the maximum torque for the entire speed range.

b) The ability to work in two directions without any additional devices.

c) The simplicity of the air cooling design.

d) The ability to operate in the generator mode.

Electric vehicles use several electric motors to drive individual wheels in order to increases the traction power of the vehicle. A series excited DC electric motors are used as traction motors [10].

\section{THE MATHEMATICAL MODEL}

Computer modeling has always been used for industrial designs, especially for EVs which have benefited greatly from the accelerated use of simulation programs in evaluating all vehicles aspects, including energy consumption. During the current study, a mathematical model of a direct current electric (DC) motor with series excitation - traction electric motor - for dynamic modes, Figure 2 was established.

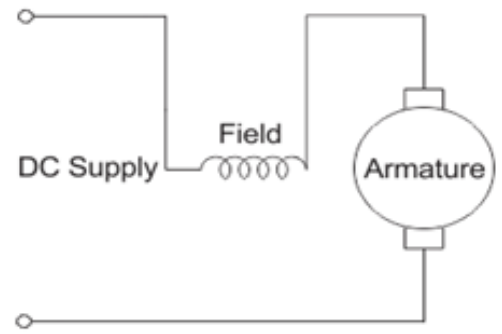

Figure 2. A schematic diagram of a direct current electric motor with series excitation

The implementation of the second Kirchhoffs' law and the basic equation of motion give the possibility of obtaining the mathematical model for a DC Motor [11] 
$i_{a} R_{t o t}+L_{t o t} \frac{d i_{a}}{d t}+E_{a}=V_{t}$

Where; $E_{a}=K \phi \omega$ is the internal induced voltage of the armature. The total resistance of the motor $\left(R_{t o t}\right)$ could be calculated from the equation:

$R_{\text {tot }}=R_{\text {arm }}+R_{\text {series }}+R_{\text {interpoles }}$

The total inductance of the motor $\left(L_{t o t}\right)$ can be easily calculated from the equation:

$L_{\text {tot }}=L_{\text {arm }}+L_{\text {series }}+L_{\text {interpoles }}$

Substituting the expression of the internal induced voltage of the motor into the second Kirchhoff law, gives:

$i_{a} R_{t o t}+L_{t o t} \frac{d i_{a}}{d t}+K \phi \omega=V_{t}$

Then, supplementing the mathematical model of the DC motor with the basic equation of motion of the electric drive can be illustrated with the following equations:

$T-T_{L}=J \frac{d \omega}{d t}$

$T=K \phi i_{a}$

The substituting of expression (4) into equation (3) gives a detailed equation of motion of the electric drive.

$K \phi i_{a}-T_{L}=J \frac{d \omega}{d t}$

Then, rewrite equations (1) and (4) to form

$$
\begin{aligned}
& \frac{d i_{a}}{d t}=\frac{1}{L_{t o t}}\left(V_{t}-i_{a} R_{t o t}-K \phi \omega\right) \\
& \frac{d \omega}{d t}=\frac{1}{J}\left(K \phi i_{a}-T_{L}\right)
\end{aligned}
$$

As a result of such transformations, a nonlinear mathematical model of the direct current electric motor with series excitation was obtained. The non-linearity of the model is related to the nonlinear characteristics of the machine's magnetic circuit, which could be attributed to the nonlinear relationship between the flux of the machine and the field current. The obtained equations in the employed model are differential equations of the first order. To solve the last two equations, Euler's' method [12] was employed. Thus, equations (6) and (7) were written as the algebraic equations (8\&9), and were then easily implemented with the computer application.

$$
\begin{aligned}
& \frac{\Delta i_{a}}{\Delta t}=\frac{1}{L_{a t}}\left(V_{t}-i_{a} R_{t o t}-K \phi \omega\right) \\
& \frac{\Delta \omega}{\Delta t}=\frac{1}{J}\left(K \phi i_{a}-T_{L}\right)
\end{aligned}
$$

The algorithm for the solution was:

$$
\Delta i_{a m}=\frac{\Delta t}{L_{a t}}\left(V_{m}-i_{a m-1} R_{t o t}-K \phi \omega_{m-1}\right)
$$


Where $\Delta i_{a m}$ is the increment of the armature current at " $m$ " step of integration; " $m$ " is the step of integration; $V_{m}$ is the voltage at " $m$ " step of integration applied to the armature circuit; $\Delta t-$ is the integration step; $i_{a m-1}$ is the value of the armature current at " $m-1$ " which refers to the previous step of integration; $\omega_{m-1}$ is the value of the angular velocity of the DC series motor on " $m-1$ " step of integration;

$i_{a m}=i_{a m-1}+\Delta i_{a m}$

Where $i_{a m}$ is the increment of the armature current at " $m$ " integration step.

$\Delta \omega_{m}=\frac{\Delta t}{J}\left(K \phi i_{a m}-T_{L m}\right)$

Where $\Delta \omega_{m}$ is the increment of the angular velocity at the " $m$ " integration step and $T_{L m}$ is the value of the load moment of the drive at the " $m$ " integration step.

$\omega_{m}=\omega_{m-1}+\Delta \omega_{m}$

Equations (10) and (12) were used for the determination of the increments in the current $\Delta i_{a m}$ and the velocity $\Delta \omega_{m}$. Equations (11) and (13) on the other hand, were used to calculate the current $i_{a m}$ and the velocity $\omega_{m}$.

\section{SIMULATION RESULTS AND ANALYSIS}

In the current investigation, two simulation models were employed and their results were evaluated. These included Excel and Matlab/Simulink [13] moldes. The main similarity between these method of simulation (Excel and Matlab/Simulink) is basically the mathematical model [14]. Excel helps in investigating the statistical and dynamic modes of energy $[15,16]$. Briefly, for simulating an electric DC motor with series excitation in a dynamic mode [17], values of the independent variable $(t)$ are introduced to column 1 of the Excel sheet, starting with the value $t=0$.

The value of the integration step - the increment $-(\Delta t)$ is determined using the empirical formula: $\Delta t \leq \frac{\tau_{\min }}{5}$

The minimal time constant $\left(\tau_{\text {min }}\right)$ is determined by comparing the values $\tau_{M}=\frac{J R_{t o t}}{C^{2}}$, and $\tau_{a}=\frac{L_{t o t}}{R_{a t}}$.

Values of $i_{a}$, obtained from equation (11), are introduced to second column (B). Values of $\left(\omega_{m}\right)$ as calculated from equation (13) are then introduced to the third column (C) of the spreadsheet. The fourth and fifth columns contained the calculated values of $\Delta i_{a m}$ and $\Delta \omega_{m}$ obtained from equations (10) and (12), respectively. Excel results are better than Matlab/Simulink for investigating the statistical modes of energy.

All calculations using the software package "Matlab" are made with variables, as with matrices [18]. The transient process time $(t)$ from 0 to the end of the transient process $T_{t p}=5 \tau_{\min }$ is given in the form of a matrix $t=\left\lfloor 0: \Delta t: T_{t p}\right\rfloor$, where,

$\Delta t=\frac{\tau_{\min }}{10}$

Performing the process of modeling of the transient process for an electrical circuit with an induction coil when turned on to a DC voltage, is demonstrated by the following example. The used mathematical model in this example is a classical solution for a linear inhomogeneous differential equation of the first order. The parameters of the electrical circuit: 
$L=1 ; V=20 ; R=10 ; \tau_{\text {arm. }}=L / R ;$ delta $=\tau_{\text {arm. }} / 10 ; T_{p p}=5 \tau_{\text {arm. }} ; t=\left\lfloor 0:\right.$ delta $\left.: T_{p p}\right\rfloor ; i=\frac{V}{R\left(1-\exp \left(-t / \tau_{\text {arm. }}\right)\right)} ;$ $\operatorname{plot}(t, i)$.

Figure 3 shows the dependence of the current in the electrical circuit with an inductance coil, when switched to a constant voltage in the transient process.

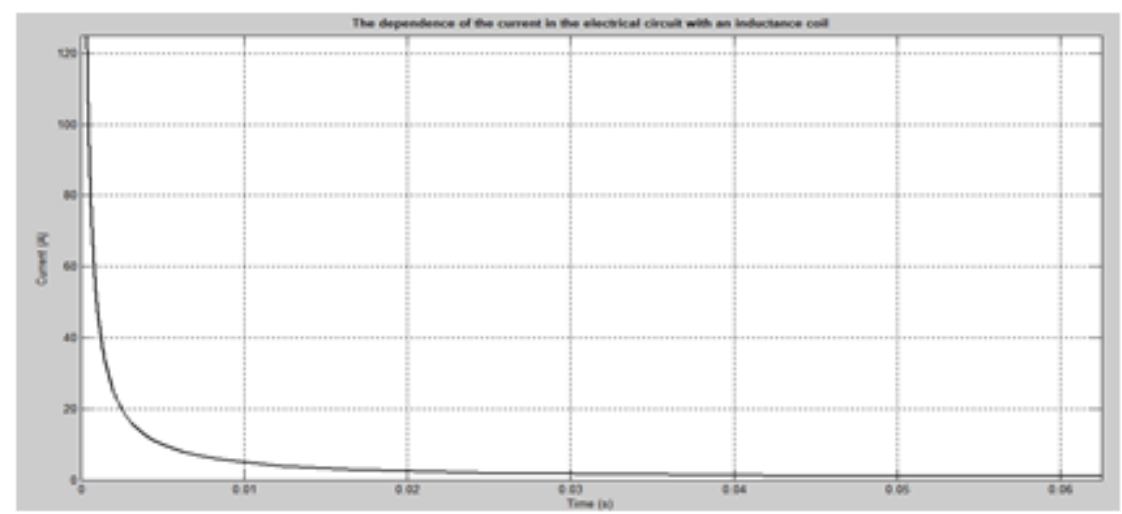

Figure 3. The dependence of the current in an electric circuit with an inductance coil

The most effective tool for mathematical modeling of electro technical objects in dynamic modes is the Matlab/Simulink [10]. Figure 4 represents a structural scheme of the mathematical model of an electric DC motor with series excitation based on equations (5) and (6).

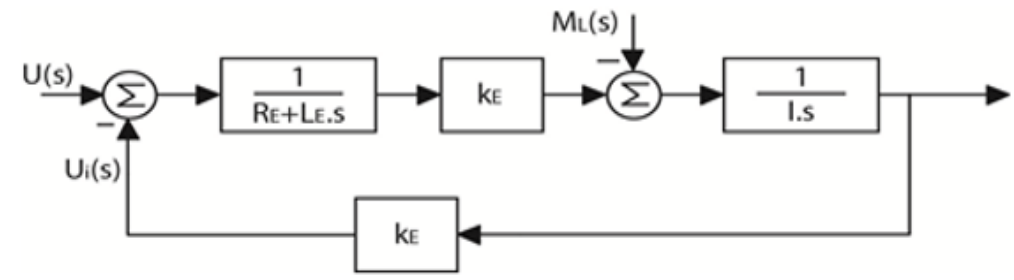

Figure 4. The mathematical model of an electric DC motor with series excitation in the form of a structural scheme.

Analysis of the scheme revealed a nonlinear model. The model contains three non-linear links, using which the motor torque (T) and the motor back EMF were determined [19]. The model of series excitated DC motor with a direct and soft-linear rising voltage-startup in the program of Matlab/Simulink is shown in Figure 5, the Matlab/Simulink Model blocks description is listed in Table 2. The motor parameters used in the current simulation study are listed in Table 1 at: A) no-load, B) 50\% rated load and C) rated load. The employed Matlab/Simuling blocks description is listed in Table 2.

Table1. Motor Parameters

\begin{tabular}{ccc}
\hline Quantity & Symbol & \\
\hline Armature Resistance & $\mathrm{Ra}$ & $0.05 \Omega$ \\
Electromechanical Time & $\mathrm{Ta}$ & $0.1 \mathrm{c}$ \\
Constant & & $10 \mathrm{Kg}-\mathrm{m}^{2}$ \\
Moment of Inertia & $\mathrm{J}$ & $200 \mathrm{Nm}$ \\
Load Torque & $\mathrm{Tl}$ & $220 \mathrm{~V}$ \\
Armature (Supply) & $\mathrm{Va}$ & \\
Voltage & & \\
\hline
\end{tabular}




\begin{tabular}{lc}
\hline & Table 2. Matlab/Simulink Model blocks description \\
\hline Scope & Display signals- Current, Torque and Speed- generated during simulation \\
Gain & Multiply input by constant \\
Math Function & Perform mathematical function \\
Product & Multiply and divide scalars and nonscalars or multiply and invert matrices \\
Sum & Add or subtract inputs \\
Constant & Generate constant value \\
Step & Generate step function as input voltage and load \\
Ramp & Generate constantly increasing input voltage \\
Transfer Function & Model linear system by transfer function for motor circuit \\
Saturation & Limit input signal to the upper and lower saturation values of input voltage \\
Selector & Select input elements from multidimensional signal to display \\
\hline
\end{tabular}

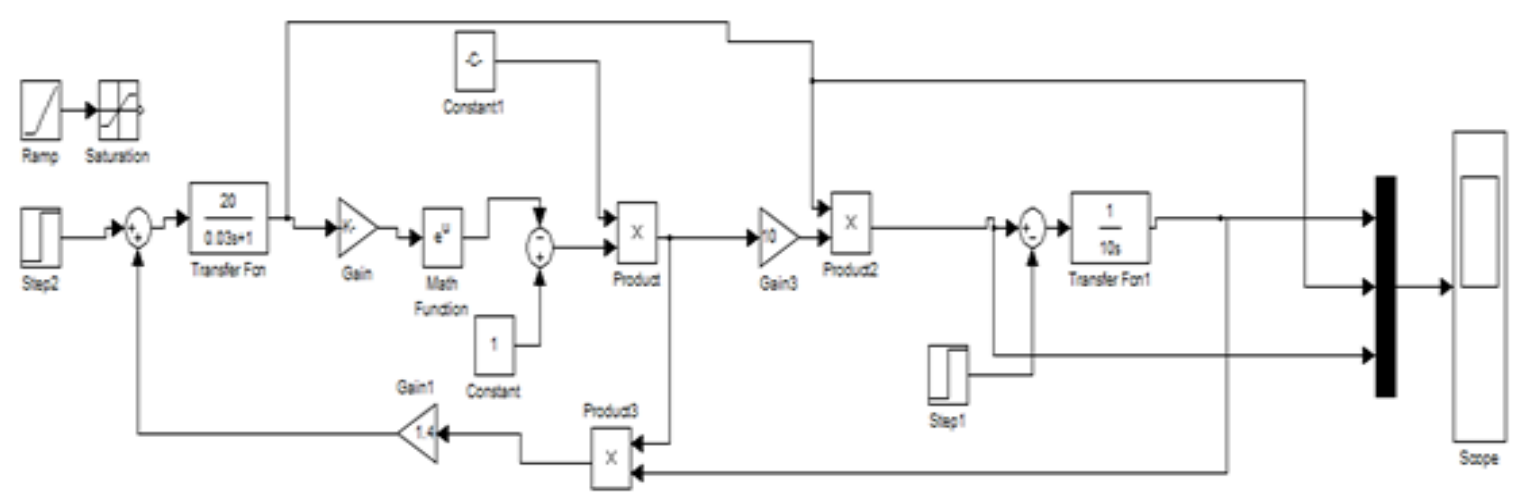

Figure 5. Matlab/Simulink mathematical model of electric DC motor with series excitation

Figure 6 shows the dependence of the angular velocity, armature current and the moment of electric DC motor with series excitation during a direct start-up obtained by the simulation in the Matlab/Simulink program. Figure 7 shows the dependence of the angular velocity, armature current and the moment of electric DC motor with series excitation during a direct start-up, obtained by simulation in the Matlab/Simulink program.

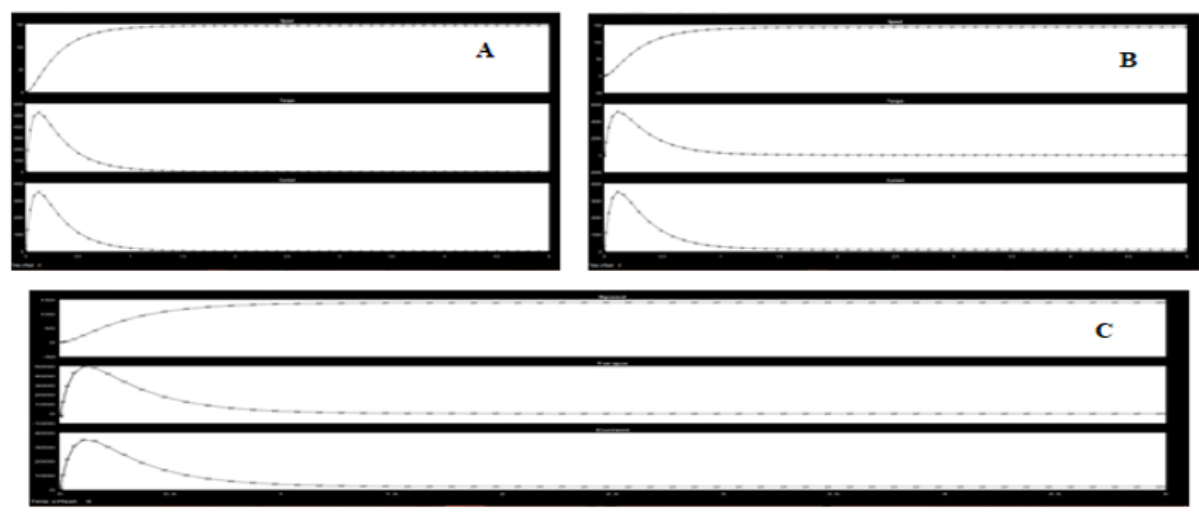

Figure 6. The direct start-up dependence of the angular velocity, the armature current and the moment of electric DC motor with series excitation at A: at no-load; B: at $50 \%$ of rated load and $\mathbf{C}$ : at rated load

As could be concluded from figures 5 and 6, the simulation results revealed that the starting current of the motor was $460 \mathrm{~A}$, but after a transient condition period, the current reached a value of $357 \mathrm{~A}$ and became stable. Similarly, at starting conditions, the motor torque reached a value of 645 N.m but after $12 \mathrm{~s}$, the motor torque was stabilized to a value of 500 N.m [6]. The figures also indicated that the speed was changing smoothly $(0-145) \mathrm{rad} / \mathrm{s}$ and was stable. The above mentioned values of current, torque and speed are for the smooth starting method [10]. 
The energy efficiency and the minimizing of the electric energy consumption in the ETS can be amplified by using regenerative braking. Depending on the nature of the roads, there is a good possibility for the utilization of regenerative braking with good dynamic performance, more recovered energy and with a chance of choosing a better control algorithm for the vehicle controller [20]. When driving on a flat road surface at a constant speed, the consumption of electric energy is the smallest. An increase in the device weight, road resistance and resistances while driving up or down the hill will decrease or increase the ability of acceleration and thus increaseing or decreasing the energy consumption during the acceleration or deacceleration. However, more energy is recovered during engine braking. Most energy is consumed during the acceleration of the electric transport device [21, 22].

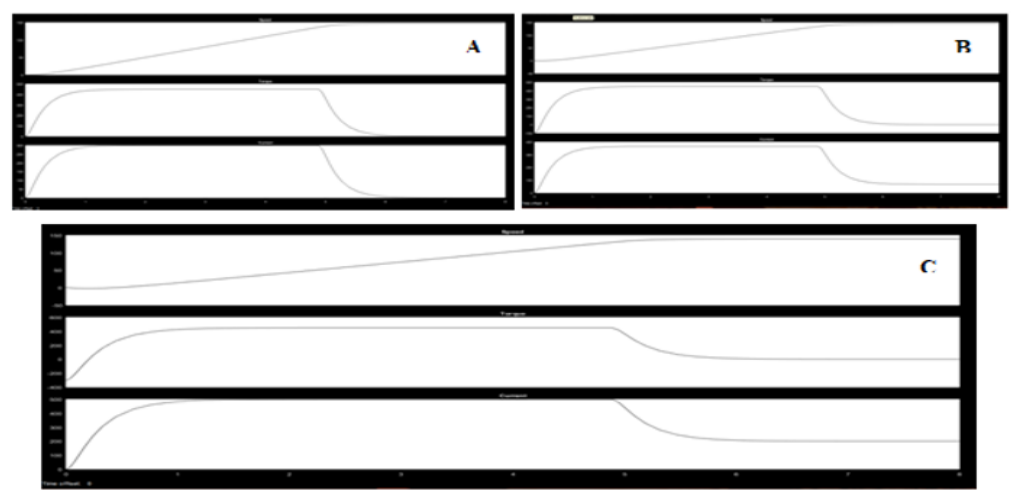

Figure 7. The start-up with a linear rising voltage (pulse-width modulation) dependence of the angular velocity, armature current and the moment of electric DC motor with series excitation: A: at no-load; B: at $50 \%$ of rated load and $\mathbf{C}$ : at rated load

The effect of sudden changes in motor load, road resistance, passengers load or road slope were also investigated, as shown in Figure 8. Results revealed that the speed, torque and current were not very sensitive to such changes indicating that the motor performance and stability were very good. The results of the current simulation study indicated that the series DC motor reached a steady state speed after a transient condition period not exceeding $1.5-2 \mathrm{~s}$ and in different loading cases of the electric transport device. The findings of the current study confirms that the Series DC Motor is covering the electric transport requirements with best dynamic performance and is suitable to be used in electric transport devices and generally for electric traction.

Figure (8) shows the dependence of the angular velocity, armature current and the moment of electric DC motor with series excitation during direct start-up and steady state conditions, obtained by simulation in the Matlab/Simulink program when the load of motor was changed during motor running, due to the road resistance and resistances while driving up or down the hill.

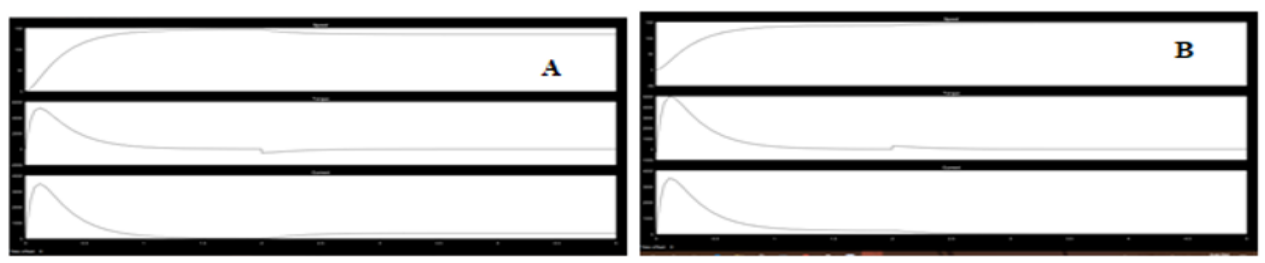

Figure 8. The direct start-up dependence of the angular velocity, the armature current and the moment of electric DC motor with series excitation when the load changing during motor running A: with load increasing (up the hill) and $\mathbf{B}$ : with load decreasing (down the hill)

\section{CONCLUSION}

The obtained characteristics by Simulink/Matlab of the investigated Series DC motor in terms of speed, current and torque are compatible with the findings of other researchers [23]. In the current work, a Matlab/Simulink mathematical model derivation for the described motor has been carefully described and 
discussed taking into consideration the nonlinear relationship between the field current and the machine flux. Simulation results obtained in the current study confirmed the feasibility of the use of the series excited DC motor (traction motor) in electric buses in transportation system as alternatives for internal combustion engine motors. The obtained characteristics for speed, current and torque indicated that the studied motor reached a steady state speed after $6 \mathrm{~s}$ at different loads. This result clearly revealed that Series tractive DC motor is very suitable in electric buses transport devices. The starting current was about $460 \mathrm{~A}$, is 8 times more than the rated current of the motor and $357 \mathrm{~A}$ in steady state condition with different loads (passengers). In general the Series DC Motor is covering the electric transport requirements and gives the best dynamic performance.

\section{REFERENCES}

[1] Baptista P, Duarte G, Goncalves G, Farias T. Evaluation of low power electric vehicles in demanding urban conditions: An application to Lisbon. The 2013 World Electric Vehicle Symposium and Exhibition (EVS27). Barcelona, Spain, 2013; 1-10.

[2] Juul N, Meibom P. Road transport and power system scenarios for Northern Europe in 2030. Appl. Energy. 2012; 92: 573-582.

[3] Fiori C, Ahn K, Rakha HA. Power-based electric vehicle energy consumption model: Model development and validation. Appl. Energy. 2016; 168: 257-268.

[4] Lukic S, Mulhall P, Emadi A. Energy autonomous solar/battery auto Rickshaw. J. Asian Electr. Veh., 2008; 6: $1135-1143$.

[5] Clegg SJ. A Review of Regenerative Braking Systems. Institute of Transport Studies, University of Leeds, Working Paper 471

[6] Xiao Y, Nemec M, Borle LJ, Sreeram V, IU HHC. Regenerative braking of series- wound brushed DC electric motors for electric Vehicles. $7^{\text {th }}$ IEEE Conference on Industrial Electronics and Applications (ICIEA). Singapore, Singapore. 2012.

[7] Malode SK, Adware RH. Regenerative braking ssystem in electric vehicles. International Research Journal of Engineering and Technology. 3(3): 349-400.

[8] http://www.venturemagazine.me/2018/01/transport-woes-managing-expectations-brt/

[9] http://www.jordantimes.com/news/local/gam-signs-deal-french-agency-fund-rapid-bus-project

[10] Wang M, Rong J, Wu X, Chen M. Liu L. The simulation study of the starting of DC motor based on MATLAB. Electronic Technol., 2013; 7: 7-9.

[11] Mohd TAT, Hassan MK, Aziz WMKA. Mathmatical modeling and simulation of an electic vehicle. Journal of Mechanical Engineering and Sciences. 2015; 8: 1312-1321.

[12] Slemon GR, Straughen AA. Electric Machines. First edition, New York: Addison Wesley Publishing Company 1982.

[13] Rudra R, Banerjee R. Modeling and simulation of DC motor speed regulation by field current control using MATLAB. International Journal of Computer Electrical Engineering. 2017; 9(2): 502-512.

[14] Zadehbagheri M, Ildarabadi R, Nejad MB. A Review on Speed Control Techniques of Separately Excited DC Motor. Indonesian Journal of Electrical Engineering and Computer Science. 2015; 13(1):65-75.

[15] Dheeraj Varma NEVR, Mittal A. Dynamic Modeling and Simulation of a Series Motor Driven Battery Electric Vehicle Integrated With an Ultra Capacitor. IOSR Journal of Electrical and Electronics Engineering. 2015; 10(3 Ver II): 79-83.

[16] Zhang L, Hao G, Yang X, Zhou C. The Electric Vehicle Power Design and The Matching Characteristics Analysis of The Transmission System. TELKOMNIKA. 2013; 11(11): 6352-6357.

[17] Xiangzheng Xu, Qi Chen. Load Characteristics Analysis and Simulation Study of Electric Locomotive, TELKOMNIKA Indonesian Journal of Electrical Engineering. 2014; 12(3): 2158- 2163.

[18] Okoro OI, Ogbuka CU, Agu MU. Simulation of D.C. Machines transient behaviors: Teaching and research. The Pacific Journal of Science and Technology, 9(1): 39-57.

[19] Xiong J, Feng Z, Liu J. Simulation and design of double close-loop DC motor control system based on MATAB. The proceeding of the International Conferance on Electrical Insulating Materials and Electrical Engineering (EIMEE), Shenyang, Liaoning. 2012; 248-253.

[20] Hannan MA, Azidin FA, Mohamed A. Multi-sources model and control algorithm of an energy management system for light electric vehicles. Energy Convers. Manag., 2012; 62: 123-130.

[21] Bitara Z, Al Jabia S, Khamis I. Modeling and simulation of series DC motors in electric Car. Energy Procedia. 2014; 50: $460-470$.

[22] Barna G. Simulation model of a series DC motor for traction rail vehicles. $201621^{\text {st }}$ International Conference on Methods and Models in Automation and Robotics (MMAR). Poland. 2016: 531-536.

[23] Zeraoulia M, El Hachemi Benbouzid M, Diallo D. Electric motor drive selection issues for HEV propulsion systems: A comparative study. IEEE Transactions on Vehicular Technology. 2006; 55(6): 280-288. 